Check for updates

Cite this: RSC Adv., 2019, 9, 37556

Received 11th September 2019 Accepted 11th November 2019

DOI: $10.1039 / c 9 r a 07307 h$

rsc.li/rsc-advances

\section{Ultrafine $\mathrm{MoO}_{2}$ nanoparticles encapsulated in a hierarchically porous carbon nanofiber film as a high-performance binder-free anode in lithium ion batteries}

\author{
Xin Chen, ${ }^{a}$ Guojun Gao, ${ }^{a}$ Zhipeng Wu, ${ }^{a}$ Jun Xiang, (D) *a Xiaoqiang Li, ${ }^{a}$ \\ Guangguang Guan ${ }^{a}$ and Kaiyin Zhang*b
}

\begin{abstract}
Flexible free-standing hierarchically porous carbon nanofibers embedded with ultrafine ( 3.5 nm) $\mathrm{MoO}_{2}$ nanoparticles (denoted as $\mathrm{MoO}_{2}$ (aHPCNFs) have been synthesized by electrospinning and subsequent heat treatment. When evaluated as a binder-free anode in Li-ion batteries, the as-obtained $\mathrm{MoO}_{2} \mathrm{QHPCNFs}$ film exhibits excellent capacity retention with high reversible capacity $\left(\geq 1055 \mathrm{~mA} \mathrm{~h} \mathrm{~g}{ }^{-1}\right.$ at $100 \mathrm{~mA} \mathrm{~g}^{-1}$ ) and good rate capability $\left(425 \mathrm{~mA} \mathrm{~h} \mathrm{~g}^{-1}\right.$ at $2000 \mathrm{~mA} \mathrm{~g}^{-1}$ ), which is much superior to most of the previously reported $\mathrm{MoO}_{2}$-based materials. The synergistic effect of uniformly dispersed ultrasmall $\mathrm{MoO}_{2}$ nanoparticles and a three-dimensionally hierarchical porous conductive network constructed by HPCNFs effectively improve the utilization rate of active materials, enhance the transport of both electrons and $\mathrm{Li}^{+}$ions, facilitate the electrolyte penetration, and promote the $\mathrm{Li}^{+}$storage kinetics and stability, thus leading to a greatly enhanced electrochemical performance.
\end{abstract}

\section{Introduction}

Rechargeable lithium ion batteries (LIBs) have attracted tremendous attention due to their huge successes in electrochemical energy storage systems. ${ }^{\mathbf{1 - 4}}$ Notwithstanding the remarkable progress achieved so far, it is still a great challenge to develop new high-performance electrode materials with high energy density, excellent cycling stability and rate capability to meet the ever-expanding demands for advanced energy storage and conversion devices. ${ }^{5}$ Until now, a large number of transition metal oxides have been exploited as promising anode materials for LIBs. ${ }^{6}$ Among various metal oxide-based electrode materials, molybdenum dioxide $\left(\mathrm{MoO}_{2}\right)$ has been widely studied because of its rich chemical and structural versatility, and high theoretical specific capacity $\left(838 \mathrm{~mA} \mathrm{~h} \mathrm{~g}^{-1}\right) .{ }^{7}$ However, bare $\mathrm{MoO}_{2}$ is not an ideal Li-storage host due to its intrinsically slow electrochemical reaction kinetics, low conductivity, and drastic volume change during cycling, leading to poor rate capability and severe capacity fading. ${ }^{8}$

To overcome these drawbacks and improve the electrochemical properties, nanosized $\mathrm{MoO}_{2}$ combined with carbon materials owning good conductivity and structural stability has been demonstrated to be an effective strategy. ${ }^{9-11}$ Among diverse

${ }^{a}$ School of Science, Jiangsu University of Science and Technology, Zhenjiang 212003, China.E-mail: jxiang@just.edu.cn

${ }^{b}$ School of Physics and Electronic Engineering, Fuyang Normal University, Fuyang 236037, China. E-mail: kyzhang@fync.edu.cn carbon materials for LIB anodes, one-dimensional carbon nanofibers (CNFs) and their derivatives have gained special attention because they can be built into a flexible porous threedimensionally (3D) conductive network for the rapid transport of both electrons and ions, significantly enhancing the electrochemical reaction kinetics and promoting the energy density and cycling stability. ${ }^{\mathbf{1 2 , 1 3}}$ Moreover, some research has indicated that the introduction of various porous structures into CNFs can further improve both the specific capacity and the rate performance of CNFs-based electrodes. ${ }^{\mathbf{1 4 , 1 5}}$ The incorporated pores can probably provide more electrode-electrolyte interface and markedly reduce electronic/ionic diffusion distance, thus further strengthening charge transport capability. In recent years, ultrasmall transition metal oxide nanoparticles loaded porous CNFs (PCNFs) have emerged as novel anode materials for LIBs. For instance, $\mathrm{TiO}_{2} @ P C N F s,{ }^{16}$ MOUNPs@HPCNFs (M $=\mathrm{Zn}, \mathrm{Mn}$, and Co), ${ }^{17} \gamma-\mathrm{Fe}_{2} \mathrm{O}_{3} / \mathrm{PCNFs},{ }^{18}$ and $\mathrm{MoO}_{3} / \mathrm{PCNFs}^{19}$ have been reported to exhibit excellent electrochemical properties. However, as far as we know, there has been no report as yet on the preparation and electrochemical performance of flexible self-supported PCNFs containing ultrasmall $\mathrm{MoO}_{2}$ nanoparticles. Therefore, it is of great interest to design and synthesize such nanostructure as binder-free anodes in LIBs.

Herein, we have proposed a novel binder-free LIB anode based on ultrafine $\mathrm{MoO}_{2}$ nanoparticles uniformly encapsulated in hierarchically porous carbon nanofibers (denoted as $\mathrm{MoO}_{2}$ @HPCNFs) prepared via a facile electrospinning approach using polymethylacrylate (PMMA) as a pore-forming 
agent, followed by a controlled reduction-carbonization process The $\mathrm{MoO}_{2} @ H P C N F s$ electrode exhibits high lithium storage capacity and rate capability, showing a great application prospect in high-performance LIBs.

\section{Experimental}

\subsection{Preparation of $\mathrm{MoO}_{2} @ H P C N F s$}

The $\mathrm{MoO}_{2} @ H P C N F s$ were prepared via co-electrospinning of polyacrylonitrile (PAN)/polymethylacrylate (PMMA)/Mo precursor combined with a controlled reduction-carbonization process, which was similar to our previous report. ${ }^{20}$ PMMA was used here as a pore generator that can be removed from the PAN-derived carbon nanofiber matrix under high temperature. $1.76 \mathrm{~g}$ of PAN $\left(M_{\mathrm{w}}=150 \mathrm{k}\right.$, Aldrich) and $0.44 \mathrm{~g}$ of PMMA $\left(M_{\mathrm{w}}=\right.$ $150 \mathrm{k}$, Aladdin) were dissolved first in $16.8 \mathrm{~g}$ of $N, N$-dimethylformamide (DMF) at $60{ }^{\circ} \mathrm{C}$ for $4 \mathrm{~h}$ under magnetic stirring. Then, $1 \mathrm{~g}$ of $\mathrm{MoCl}_{5}$ was added into the mixture solution and further stirred approximately $12 \mathrm{~h}$ at room temperature to obtain a homogeneous solution for electrospinning. The precursor solution was transferred into a $20 \mathrm{~mL}$ plastic syringe and was electrospun by using a TL-01 electrospinning apparatus under the applied voltage of $18 \mathrm{kV}$, solution feeding rate of $0.4 \mathrm{~mL} \mathrm{~h}^{-1}$ and collector distance of $18 \mathrm{~cm}$. The as-spun fibers were collected by an aluminum foil enwrapped roller with a rotate speed of about $300 \mathrm{rpm}$. The formed fiber film was subsequently stabilized at $220^{\circ} \mathrm{C}$ for $4 \mathrm{~h}$ under air atmosphere and finally carbonized at $600{ }^{\circ} \mathrm{C}$ for $5 \mathrm{~h}$ in a flowing $\mathrm{N}_{2} / \mathrm{H}_{2}(5: 1$, $\mathrm{v} / \mathrm{v}$ ) mixed atmosphere to yield the resulting product.

\subsection{Characterization}

The phase structure of as-prepared $\mathrm{MoO}_{2} @ H P C N F$ was analyzed by X-ray diffraction (XRD, Shimadzu, XRD-6000). The surface morphology and microstructure of the sample were observed using field-emission scanning electron microscope (FESEM, Zeiss, Merlin Compact) and high-resolution transmission electron microscope (HRTEM, JEOL, JEM-2001F). Raman spectrum was collected at ambient temperature on a Raman spectrometer (Renishaw, inVia Reflex) using $532 \mathrm{~nm}$ excitation wavelength. Thermogravimetric analysis (TGA) was conducted on a TGA apparatus (Shimadzu, DTG-60H) in air. Xray photoelectron spectroscopy (XPS) measurement was performed on a Thermo Fisher Scientific ESCALAB 250Xi XPS System with a monochromatic Al Ka X-ray source. Nitrogen adsorption/desorption isotherms (BET technique) at $77 \mathrm{~K}$ were recorded on a Micromeritics ASAP 2020 analyzer to characterize the pore structure of the product.

\subsection{Electrochemical measurements}

The obtained $\mathrm{MoO}_{2} @ H P C N F s$ film was punched into circular discs and directly utilized as binder-free anodes for electrochemical measurements using CR2025 coin-type cells assembled in a highly pure argon-filled glovebox. Lithium metal foil was employed as the counter electrode, Celgard 2400 microporous polypropylene membrane as the separator, and $1 \mathrm{M}$ $\mathrm{LiPF}_{6}$ in a mixture of ethylene carbonate (EC), ethyl methyl carbonate (EMC) and dimethylcarbonate (DMC) $(1: 1: 1, \mathrm{v} / \mathrm{v} / \mathrm{v})$ as the electrolyte. The galvanostatic charge/discharge tests were carried out on a Land CT2001A battery testing system within the voltage range of $0.01-3.0 \mathrm{~V} v s . \mathrm{Li}^{+} / \mathrm{Li}$ at different current densities. Cyclic voltammetry (CV) was measured by using a BioLogic SP-300 electrochemical workstation between $0.01-3.0 \mathrm{~V} v s . \mathrm{Li}^{+} /$ $\mathrm{Li}$ at a scan rate of $0.1 \mathrm{mV} \mathrm{S}^{-1}$. The mass of self-standing $\mathrm{MoO}_{2} @ H P C N F s$ film electrode is around $3 \mathrm{mg}$, and all the specific capacities are calculated based on the total mass of $\mathrm{MoO}_{2} @ H P C N F s$ film in this paper.

\section{Results and discussion}

Fig. 1a shows the XRD pattern of $\mathrm{MoO}_{2} @ H P C N F s$. All the distinct diffraction peaks can be indexed to the monoclinic structure of $\mathrm{MoO}_{2}$ (JCPDS no. 73-1249), and no other distinguishable crystalline peaks belonging to molybdenum carbide/ nitride are detected in the pattern, suggesting the high purity of the sample. In addition, a broad peak at low angle rang in the baseline can be clearly observed, demonstrating that the HPCNFs matrix is mainly amorphous. The structural information of carbon is further investigated using Raman spectra as presented in Fig. 1b. The as-prepared sample displays two wide peaks located at about 1324 and $1586 \mathrm{~cm}^{-1}$, known as the Dband and G-band, corresponding to the disordered carbon and graphite carbon, respectively. ${ }^{21}$ This result indicates that the sample is partially graphitized during the carbonization process. A large number of defects and vacancies in amorphous carbon can offer more diffusion channels and intercalation sites for $\mathrm{Li}^{+}$storage, and meanwhile the appearance of graphite carbon can endow the whole film electrode with better conductivity, both of which would contribute to the overall capacity. ${ }^{17,22}$ The mass fraction of $\mathrm{MoO}_{2}$ in the $\mathrm{MoO}_{2} @ H P C N F s$ is determined by TGA (Fig. 1c). A small weight loss of $6.5 \mathrm{wt} \%$ before $170{ }^{\circ} \mathrm{C}$ in the TG curve may be attributed to the evaporation of the absorbed water. The large weight loss of $72.7 \mathrm{wt} \%$ from 290 to $510{ }^{\circ} \mathrm{C}$ is caused by the combustion of carbon. Consequently, the content of $\mathrm{MoO}_{2}$ in the $\mathrm{MoO}_{2} @ H P C N F s$ is estimated to be about $22.4 \mathrm{wt} \%$.

XPS technique was utilized to analyze the composition and valence states of $\mathrm{MoO}_{2} @$ HPCNFs. As shown in Fig. 1d, the survey spectrum reveals that the composite is composed of $\mathrm{O}, \mathrm{C}$ and Mo elements. The high-resolution Mo 3d spectrum (Fig. 1e) can be fitted to two doublets. ${ }^{23}$ One doublet with low energy and high intensity centered at 235.9 and $232.8 \mathrm{eV}$ are ascribed to $\operatorname{Mo}(\mathrm{Iv}) 3 \mathrm{~d}_{3 / 2}$ and $\operatorname{Mo}(\mathrm{Iv}) 3 \mathrm{~d}_{5 / 2}$, respectively, further confirming the formation of $\mathrm{MoO}_{2}$. The other doublet with high energy and low intensity at 236.5 and $233.4 \mathrm{eV}$ arise from $\mathrm{Mo}(\mathrm{vI}) 3 \mathrm{~d}_{3 / 2}$ and $\mathrm{Mo}(\mathrm{vI}) 3 \mathrm{~d}_{5 / 2}$ of $\mathrm{MoO}_{3}$, probably due to the slight surface oxidation of metastable $\mathrm{MoO}_{2}$ in air. Nevertheless, the XRD spectrum in Fig. 1a do not display any peaks coming from $\mathrm{MoO}_{3}$, which may be because of the low content of $\mathrm{MoO}_{3}$ or its amorphous nature in the product.

Fig. 2a presents the SEM image of $\mathrm{MoO}_{2}$ @HPCNFs. The HPCNFs have smooth surface and continuous 1D structure with a mean diameter of $420 \pm 50 \mathrm{~nm}$ and length of up to several hundred microns, which are randomly oriented and interlinked 

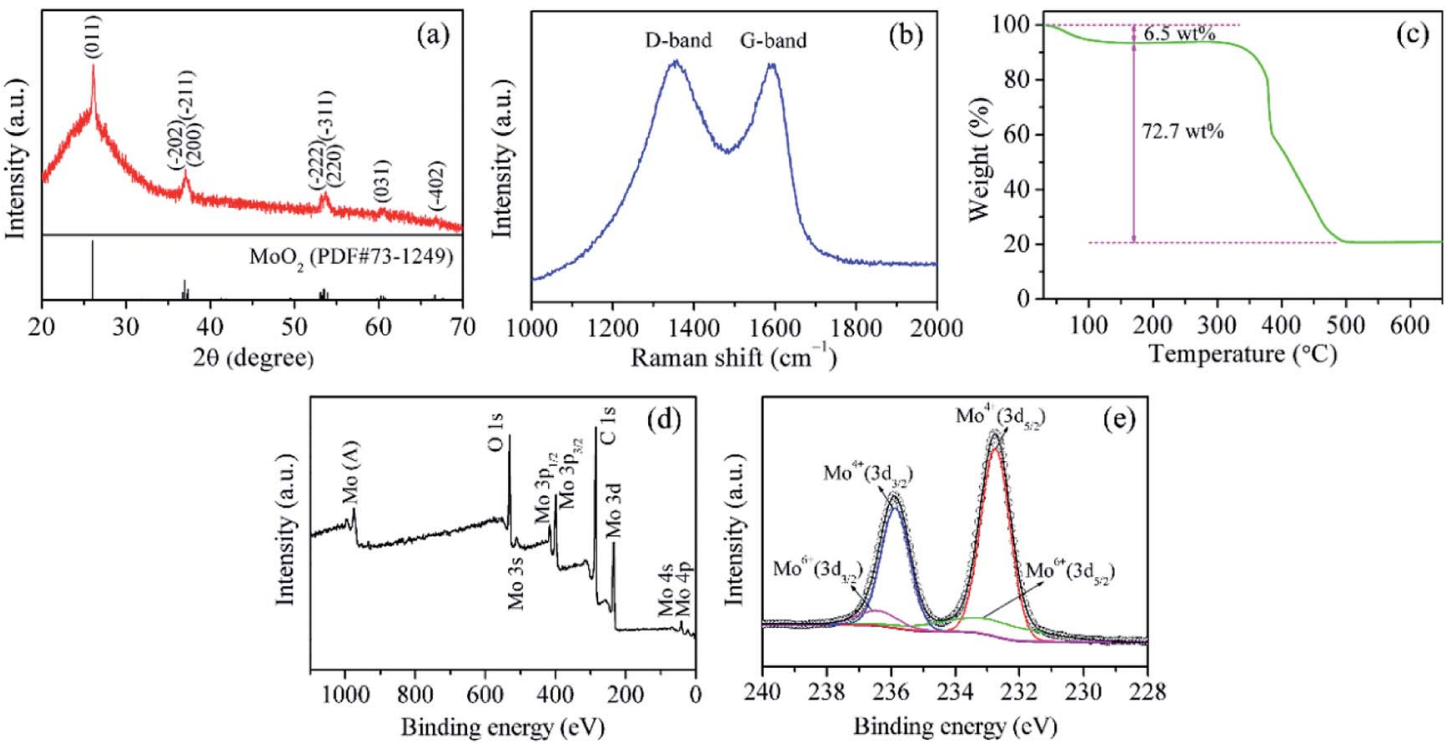

Fig. 1 (a) XRD pattern, (b) Raman spectrum, (c) TG curve, (d) XPS survey spectrum, and (e) high-resolution Mo 3d spectrum of MoO $\mathrm{CH}_{2}$ (a)CNF.

into a porous 3D conductive network. Such architecture can endow the electrode with improved cell reaction kinetics and structural integrity for lithium insertion/extraction. ${ }^{24}$ Furthermore, the cross-section SEM image (Fig. 2b) reveals that there are numerous mesopores and macropores inside the HPCNFs. The TEM image (Fig. 2d) further verifies this result, and we can also see that the partial $\mathrm{MoO}_{2} @ H P C N F s$ have a hollow structure possibly due to the connection of some channel-like macropores. The nitrogen adsorption-desorption isotherm of $\mathrm{MoO}_{2} @ H P C N F s$ (Fig. 2c) shows a typical type-IV behavior with an obvious hysteresis loop corresponding to the mesoporous structure, and meanwhile the isotherm displays a steep uptake at high relative pressures $\left(P / P_{0}>0.8\right)$, also indicating the existence of macroporous structure in the material, ${ }^{25}$ which are well accord with the FESEM and TEM observations. By using the BET method, the total pore volume and specific surface area of $\mathrm{MoO}_{2} @ H P C N F s$ are approximately $0.13 \mathrm{~cm}^{3} \mathrm{~g}^{-1}$ and $56.6 \mathrm{~m}^{2}$ $\mathrm{g}^{-1}$, respectively. The abundant mesopores and macropores throughout the HPCNFs not only enable the electrode more fully accessible to the electrolyte and take full advantage of the dispersed high-capacity $\mathrm{MoO}_{2}$ nanoparticles, but also effectively tolerate the mechanical stress caused by volume change and
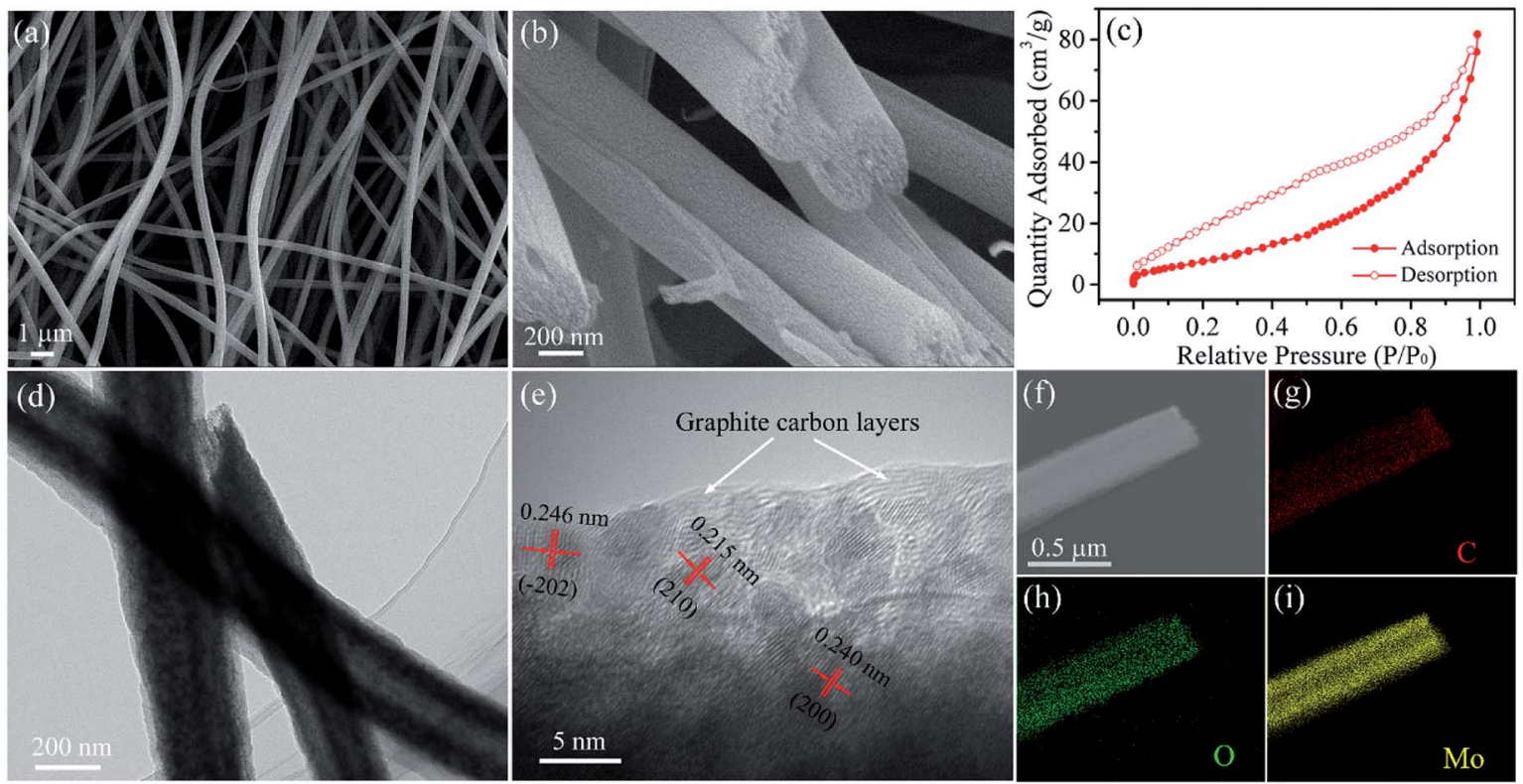

Fig. 2 (a) Surface and (b) cross-sectional SEM images, (c) nitrogen adsorption-desorption isotherm, (d) TEM, (e) HRTEM, (f) STEM and (g-i) corresponding elemental mapping images of $\mathrm{MoO}_{2}$ (aHPCNFs. 

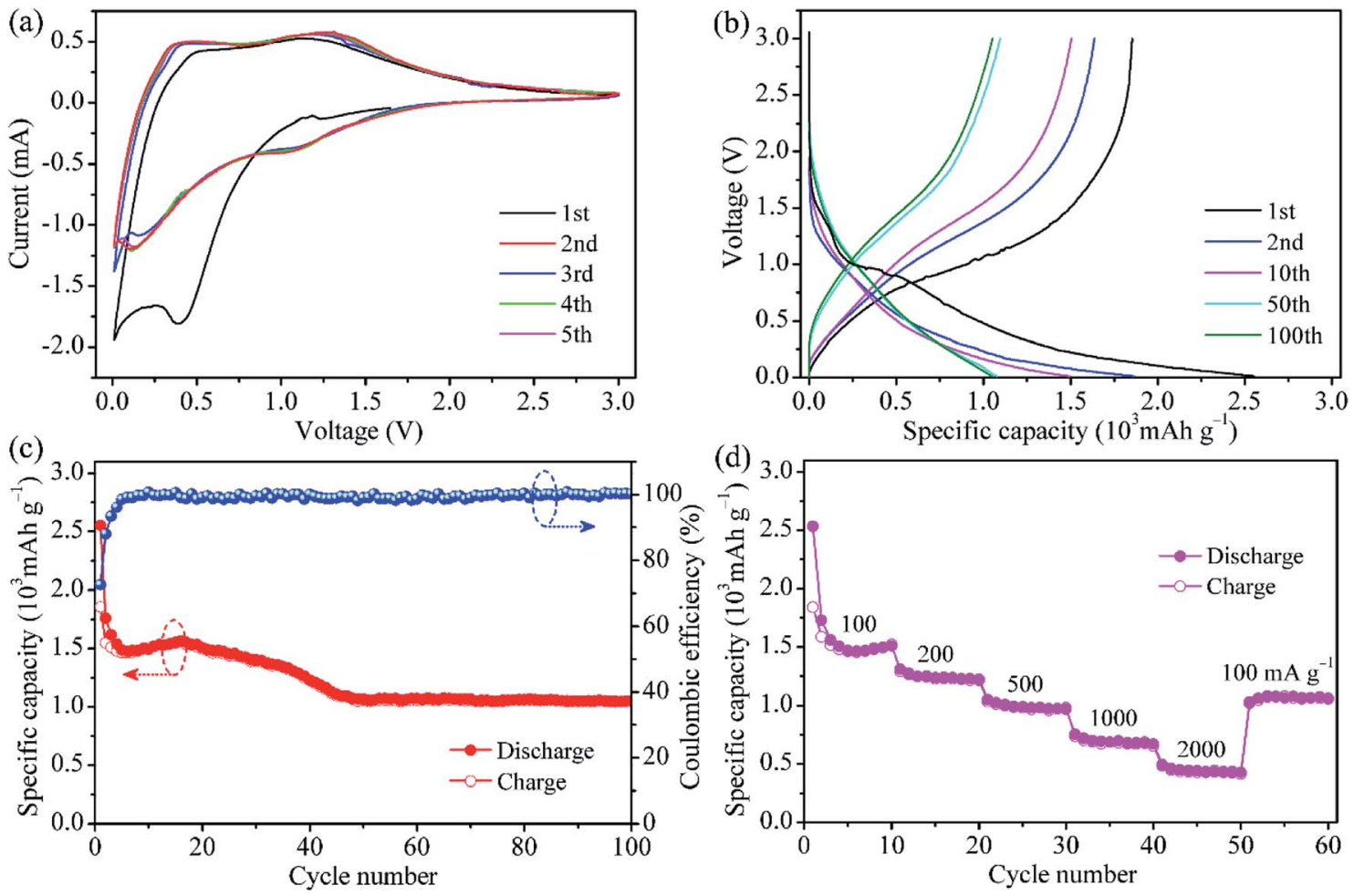

Fig. 3 (a) Cyclic voltammograms, (b) galvanostatic discharge/charge curves for selected cycles at $100 \mathrm{~mA} \mathrm{~g}^{-1}$, (c) cycling performance and coulombic efficiency at $100 \mathrm{~mA} \mathrm{~g}^{-1}$, and (d) rate capacities at various current densities for the $\mathrm{MoO}_{2}$ (aHPCNFs film electrode.

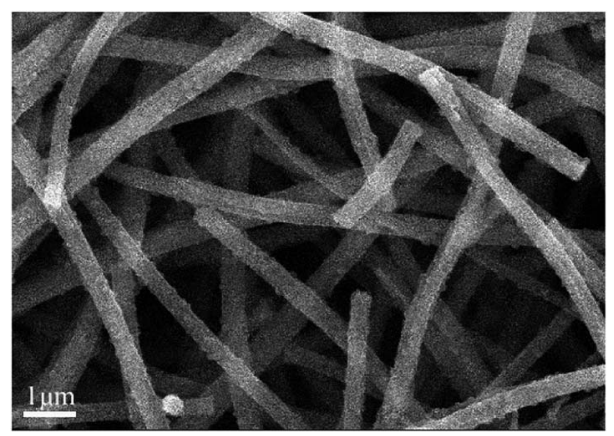

Fig. 4 SEM image of the $\mathrm{MoO}_{2}$ (aHPCNFs film electrode after 100 cycles at $100 \mathrm{~mA} \mathrm{~g}^{-1}$.

prevent the nanoparticle pulverization/aggregation during cycling, which will be conducive to achieving an enhanced and stable electrochemical performance. ${ }^{26}$ The HRTEM image (Fig. 2e) reveals that the obtained ultrasmall $\mathrm{MoO}_{2}$ nanoparticles have a uniform particle size of about $3.5 \mathrm{~nm}$ and are homogeneously embedded in the HPCNFs. In addition, the distinct lattice fringes are observed in the HRTEM image, suggesting a comparatively high crystallinity of $\mathrm{MoO}_{2}$ nanoparticles. The measured interplanar spacings of $0.215,0.240$ and $0.246 \mathrm{~nm}$ can be assigned to the (210), (200) and (-202) planes of monoclinic $\mathrm{MoO}_{2}$, respectively. Moreover, the clear lattice fringes belonging to the graphitic carbon can be observed, which further validates the existence of graphitized carbon in HPCNFs and is well consistent with the Raman results. As shown in Fig. $2 \mathrm{f}-\mathrm{i}$, the scanning TEM (STEM) and corresponding elemental mapping images demonstrate the homogeneous distribution $\mathrm{O}$ and Mo elements along the HPCNFs, confirming that the $\mathrm{MoO}_{2}$ nanoparticles with ultrasmall size are evenly dispersed throughout the HPCNFs from another angle. It should be emphasized that such a homogeneous distribution of ultrafine $\mathrm{MoO}_{2}$ nanoparticles inside the HPCNFs can facilitate the charge transfer and $\mathrm{Li}^{+}$ion diffusion kinetics due to the shortened conducting and diffusion paths. ${ }^{17}$

The typical CV curves of $\mathrm{MoO}_{2} @ H P C N F s$ film for the initial five cycles are presented in Fig. 3a. In the first cathodic sweep, a broad and large peak at approximately $0.4 \mathrm{~V}$ is observed, which is ascribed to the irreversible formation of solid electrolyte interphase (SEI) film on the HPCNFs surfaces. ${ }^{27}$ During the subsequent cycles, this peak disappears and one redox couple at about 1.31/1.05 V corresponding to the reversible phase transition of partially lithiated $\mathrm{Li}_{x} \mathrm{MoO}_{2}$ become relatively distinct. ${ }^{28,29}$ At the potential above $1{\mathrm{~V}, \mathrm{Li}^{+}}^{+}$is intercalated into $\mathrm{MoO}_{2}$ to form the solid solution $\mathrm{Li}_{x} \mathrm{MoO}_{2} \cdot{ }^{23}$ As the electrode is discharged below $1 \mathrm{~V}$, the as-formed $\mathrm{Li}_{x} \mathrm{MoO}_{2}$ would reaction with $\mathrm{Li}^{+}$and be gradually converted into metallic $\mathrm{Mo}$ and $\mathrm{Li}_{2} \mathrm{O}$. From the second cycles onwards, a clear reduction peak appears at around $0.12 \mathrm{~V}$, possibly indicating a more complete conversion reaction from $\mathrm{Li}_{x} \mathrm{MoO}_{2}$ to $\mathrm{Mo}$ and $\mathrm{Li}_{2} \mathrm{O} .{ }^{9}$ It is worth pointing out that after the first cycle, the $\mathrm{CV}$ curves nearly overlap, suggesting the good Li insertion/extraction reversibility of the $\mathrm{MoO}_{2} @ H P C N F$ s electrode. In addition, no visible lithiation/delithiation peaks related to the carbon matrix are 
Table 1 Comparison on electrochemical properties of $\mathrm{MoO}_{2}\left(\mathrm{aHPCNFs}\right.$ and some other $\mathrm{MoO}_{2}$-based anode materials

\begin{tabular}{|c|c|c|c|}
\hline Sample ${ }^{\text {ref. }}$ & $\begin{array}{l}\text { Current density } \\
\left(\mathrm{mA} \mathrm{g}^{-1}\right)\end{array}$ & $\begin{array}{l}\text { Capacity (mA h } \\
\mathrm{g}^{-1} \text { ) }\end{array}$ & Cycle number \\
\hline $\mathrm{MoO}_{2} / \mathrm{CNFs}^{18}$ & 100 & 811 & 100 \\
\hline Hierarchical $\mathrm{MoO}_{2}$ microspheres ${ }^{32}$ & 100 & 709 & 60 \\
\hline Carbon-coated $\mathrm{MoO}_{2}$ nanocrystals ${ }^{33}$ & 200 & 629 & 50 \\
\hline Carbon coated $\mathrm{MoO}_{2}$ nanofibers ${ }^{34}$ & 50 & 762.7 & 100 \\
\hline $\mathrm{MoO}_{2} /$ graphene ${ }^{37}$ & 60 & 765.3 & 40 \\
\hline $\mathrm{Mo}_{2} \mathrm{~N}$ nanolayer coated $\mathrm{MoO}_{2}$ hollow nanostructures ${ }^{38}$ & 100 & 815 & 100 \\
\hline Meso-MoO $/ \mathrm{MGO}^{39}$ & 100 & 801 & 50 \\
\hline Present work & 100 & 1055 & 100 \\
\hline
\end{tabular}

observed below $0.3 \mathrm{~V}$, implying its small contribution to the capacity.

Fig. 3b presents the galvanostatic charge/discharge profiles of $\mathrm{MoO}_{2} @ H P C N F s$ at $100 \mathrm{~mA} \mathrm{~g}^{-1}$. During the first cycle, the $\mathrm{MoO}_{2} @ H P C N F s$ electrode delivers large discharge/charge capacities of $2552 / 1854 \mathrm{~mA} \mathrm{~h} \mathrm{~g}^{-1}$ with a relatively high initial coulombic efficiency of $72.6 \%$, which indicated that the detrimental reactions between $\mathrm{MoO}_{2}$ and electrolyte can be significantly alleviated in the $\mathrm{MoO}_{2} @ H P C N F$ s. The initial capacity loss is generally attributed to the formation of SEI film and the trapping of $\mathrm{Li}^{+}$in the lattices of $\mathrm{MoO}_{2}{ }^{9,11}$ Furthermore, a discharge plateau corresponding to SEI formation is clearly observed and then disappears after the first cycle, which is in good agreement with the CV results. From the 50th cycle, the discharge/charge curves mostly overlap and the capacity remains nearly constant.

Fig. 3c shows the cycling performance of $\mathrm{MoO}_{2} @ H P C N F s$ at $100 \mathrm{~mA} \mathrm{~g}^{-1}$. The slight rise in discharge capacity from 6th to 16th cycle is ascribed to the infiltration of electrolyte and activation of materials. Then, the discharge capacity decreases gradually upon continuous cycling, which may be due to the SEI layer unstability and electrolyte degradation..$^{30}$ The capacity finally remains stable with negligible fading after 50 cycles. The anode can deliver a high reversible capacity of $1055 \mathrm{~mA} \mathrm{~h} \mathrm{~g}^{-1}$ at the 100th cycle, which is obviously higher than the theoretical capacity $\left(838 \mathrm{~mA} \mathrm{~h} \mathrm{~g}^{-1}\right)$ of neat $\mathrm{MoO}_{2}$, demonstrating the efficiently synergistic effect between ultrafine $\mathrm{MoO}_{2}$ nano-particles and HPCNFs. Furthermore, it needs to be mentioned that the coulombic efficiency reaches approximately $99 \%$ after only a few cycles and maintains relatively stable in the subsequent cycles, implying a high electrochemical reversibility and structural stability of $\mathrm{MoO}_{2}$ @HPCNFs.

The rate capability of the $\mathrm{MoO}_{2} @ H P C N F s$ electrode is illustrated in Fig. 3d. When the current density is increased, the $\mathrm{MoO}_{2} @ H P C N F s$ electrode displays a gradual reduction in the capacity. The specific reversible capacities are about 1510, 1224, 968, 669 and $425 \mathrm{~mA} \mathrm{~h} \mathrm{~g}{ }^{-1}$ at 100, 200, 500, 1000 and $2000 \mathrm{~mA} \mathrm{~g}^{-1}$, respectively. More importantly, as the current density is returned to $100 \mathrm{~mA} \mathrm{~g}^{-1}$ even after a high-rate test, the electrode still maintains stable cycling with a reversible capacity of $1060 \mathrm{~mA} \mathrm{~h} \mathrm{~g}^{-1}$, indicating the excellent rate performance and strong tolerance for the rapid $\mathrm{Li}$ insertion/extraction reaction.

To evaluate the morphological change in the $\mathrm{MoO}_{2} @-$ HPCNFs film electrode after 100 charging/discharging cycles at $100 \mathrm{~mA} \mathrm{~g}^{-1}$, SEM analysis was conducted as shown in Fig. 4. The SEM image clearly reveals that the fibrous morphology of $\mathrm{MoO}_{2} @ H P C N F s$ and the formed 3D porous network structure are well-preserved after cycling, which further demonstrates that the as-prepared $\mathrm{MoO}_{2} @ H P C N F s$ film electrode has good structural integrity during continuous lithiation and delithiation processes.

Considering the specific capacity and rate capability, the $\mathrm{MoO}_{2} @ H P C N F s$ film electrode is clearly superior to the previously reported $\mathrm{MoO}_{2} / \mathrm{CNFs}$ prepared without using poreforming agent and many other $\mathrm{MoO}_{2}$-based anode materials (Table 1). We believe the enhanced electrochemical performance of $\mathrm{MoO}_{2} @ H P C N F s$ should be mainly attribute to the 3D hierarchical structure and synergistic effect. The ultrasmall $\mathrm{MoO}_{2}$ nanoparticles can be more effectively utilized for Listorage and can enhance the Li uptake/release kinetics due to the short diffusion pathways. Meanwhile, the abundant meso/ macropores in the HPCNFs are able to offer more active sites for Li-storage, and also facilitate the electrolyte penetrate into the inner part of HPCNFs, improving the electrolyte/electrode contacting area. Moreover, the porous 3D conductive network interconnected by HPCNFs is able to provide an efficient and rapid 3D channel for the transportation of both $\mathrm{Li}$ ions and electrons, which would increase the electrochemical conductivity and decrease the internal resistance of the $\mathrm{MoO}_{2}$ @HPCNFs electrode. In addition, the combination of hierarchical pores with flexible CNFs matrix may mitigate the pulverization/ aggregation of $\mathrm{MoO}_{2}$ nanoparticles caused by volume change and preserve the structural integrity of the whole film electrode. The combined action of all the above factors leads to the high Li-storage performance of $\mathrm{MoO}_{2} @ H P C N F s$ film.

\section{Conclusions}

In summary, a novel binder-free anode made of flexible selfsupporting $\mathrm{MoO}_{2}$ @HPCNFs film has been prepared by the combination of electrospinning with controlled reduction- 
carbonization process, in which uniform ultrasmall $\mathrm{MoO}_{2}$ nanoparticles $(\sim 3.5 \mathrm{~nm})$ and plentiful meso/macropores are simultaneously formed and homogenously distributed inside the HPCNFs. Such unique structure endows the composite with a relatively higher reversible capacity and improved rate capability compared to many other $\mathrm{MoO}_{2}$-based anode materials. The $\mathrm{MoO}_{2} @ H P C N F s$ electrode can deliver a high reversible capacity of $1055 \mathrm{~mA} \mathrm{~h} \mathrm{~g}^{-1}$ after 100 cycles at $100 \mathrm{~mA} \mathrm{~g}^{-1}$, and it still remains $425 \mathrm{~mA} \mathrm{~h} \mathrm{~g}{ }^{-1}$ even at a high current rate of $2000 \mathrm{~mA} \mathrm{~g}^{-1}$. The enhanced electrochemical performance for the $\mathrm{MoO}_{2} @ H P C N F s$ film is the end product of the synergistic effect of well-distributed ultrafine $\mathrm{MoO}_{2}$ nanoparticles and flexible porous 3D conductive network interlinked by HPCNFs, making it a promising anode candidate for LIBs worthy of indepth study.

\section{Conflicts of interest}

There are no conflicts to declare.

\section{Acknowledgements}

This work was financially supported by the Natural Science Foundation of Jiangsu Province, China (Grant No. BK20171307) and the Postgraduate Research \& Practice Innovation Program of Jiangsu Province (Grant No. SJKY19-2634).

\section{Notes and references}

1 T. Kim, W. T. Song, D. Y. Son, L. K. Ono and Y. B. Qi, J. Mater. Chem. A, 2019, 7, 2942.

2 B. Huang, Z. F. Pan, X. Y. Su and L. An, J. Power Sources, 2018, 399, 274.

3 X. Y. Deng, X. F. Chen, Y. Huang, B. B. Xiao and H. Y. Du, J. Phys. Chem. C, 2019, 123, 4721.

4 Y. Yan, F. H. Du, X. P. Shen, Z. Y. Ji, H. Zhou and G. X. Zhu, Dalton Trans., 2014, 43, 17544.

5 L. M. Zhou, K. Zhang, Z. Hu, Z. L. Tao, L. Q. Mai, Y. M. Kang, S. L. Chou and J. Chen, Adv. Energy Mater., 2018, 8, 1701415.

6 M. B. Zheng, H. Tang, L. L. Li, Q. Hu, L. Zhang, H. G. Xue and H. Pang, Adv. Sci., 2018, 5, 1700592.

7 X. C. Pan, S. T. Li, Z. M. Wang, L. Y. Yang, K. J. Zhu, L. Ren, M. Lei and J. Liu, Mater. Lett., 2017, 199, 139.

8 H. J. Zhang, K. X. Wang, X. Y. Wu, Y. M. Jiang, Y. B. Zhai, C. Wang, X. Wei and J. S. Chen, Adv. Funct. Mater., 2014, 24, 3399.

9 L. C. Yang, W. Sun, Z. W. Zhong, J. W. Liu, Q. S. Gao, R. Z. Hu and M. Zhu, J. Power Sources, 2016, 306, 78.

10 X. Wang, Y. Xiao, J. Q. Wang, L. N. Sun and M. H. Cao, J. Power Sources, 2015, 274, 142.

11 X. X. Liu, H. H. Xu, Y. H. Huang and X. L. Hu, Phys. Chem. Chem. Phys., 2016, 18, 19832.

12 Y. L. Chen, Y. Hu, Z. Shen, R. Z. Chen, X. He, X. W. Zhang, Y. Q. Li and K. S. Wu, J. Power Sources, 2017, 342, 467.

13 T. T. Yu, H. L. Liu, M. Huang, J. H. Zhang, D. Q. Su, Z. H. Tang, J. F. Xie, Y. J. Liu, A. H. Yuan and Q. H. Kong, $R S C A d v .$, 2017, 7, 51807.
14 W. H. Li, M. S. Li, K. R. Adair, X. L. Sun and Y. Yu, J. Mater. Chem. A, 2017, 5, 13882.

15 X. Y. Qian, L. Jin, S. W. Wang, S. S. Yao, D. W. Rao, X. Q. Shen, X. M. Xi and J. Xiang, RSC Adv., 2016, 6, 94629.

16 L. Zungia, V. Agubra, D. Flores, H. Campos, J. Villareal and M. Alcoutlabi, J. Alloys Compd., 2016, 686, 733.

17 G. L. Xia, L. J. Zhang, F. Fang, D. L. Sun, Z. P. Guo, H. K. Liu and X. B. Yu, Adv. Funct. Mater., 2016, 26, 6188.

18 Y. J. Chen, X. T. Yuan, C. Yang, Y. B. Lian, A. A. Razzaq, R. Shah, J. Guo, X. H. Zhao, Y. Peng and Z. Deng, J. Alloys Compd., 2019, 777, 127.

19 X. Liu, Y. Liu, X. D. Yan, J. L. Lan, Y. H. Yu and X. P. Yang, Mater. Chem. Front., 2019, 9, 120.

20 J. Xiang, Z. P. Wu, X. K. Zhang and S. S. Yao, Mater. Res. Bull., 2018, 100, 254.

21 P. Fan, T. S. Mu, S. F. Lou, X. Q. Cheng, Y. Z. Gao, C. Y. Du, P. J. Zuo, Y. L. Ma and G. P. Yin, Electrochim. Acta, 2019, 306, 590.

22 Z. W. Xu, L. Y. Wang, W. Wang, N. Li, C. Chen, C. Y. Li, C. Y. Yang, H. J. Fu and L. Y. Kuang, Electrochim. Acta, 2016, 222, 385.

23 A. Bhaskar, M. Deepa and T. N. Rao, ACS Appl. Mater. Interfaces, 2013, 5, 2555.

24 F. L. Yan, X. Tang, Y. H. Wei, L. B. Chen, G. Z. Cao, M. Zhang and T. H. Wang, J. Mater. Chem. A, 2015, 3, 12672.

25 P. T. Xie, H. Y. Li, B. He, F. Dang, J. Lin, R. H. Fan, C. X. Hou, H. Liu, J. X. Zhang, Y. Ma and Z. H. Guo, J. Mater. Chem. C, 2018, 6, 8812.

26 Q. L. Wei, F. Y. Xiong, S. S. Tan, L. Huang, E. H. Lan, B. Dunn and L. Q. Mai, Adv. Mater., 2017, 29, 1602300.

27 Y. C. Liu, N. Zhang, C. M. Yu, L. F. Jiao and J. Chen, Nano Lett., 2016, 16, 3321.

28 Z. Chen, T. Yang, H. M. Shi, T. H. Wang, M. Zhang and G. Z. Cao, Adv. Mater. Interfaces, 2017, 4, 1600816.

29 Y. M. Sun, X. L. Hu, W. Luo and Y. H. Huang, ACS Nano, 2011, 5, 7100.

30 Y. H. Dou, J. T. Xu, B. Y. Ruan, Q. N. Liu, Y. D. Pan, Z. Q. Sun and S. X. Dou, Adv. Energy Mater., 2016, 6, 1501835.

31 S. S. Tang, L. Y. Yang, J. Liu and D. Fichou, Mater. Res. Bull., 2018, 102, 277.

32 W. K. Zhai, Y. M. Xu, X. L. Cheng, S. Gao, X. F. Zhang, H. Zhao and L. H. Huo, Mater. Lett., 2015, 145, 287.

33 L. Zhou, H. B. Wu, Z. Y. Wang and X. W. Lou, ACS Appl. Mater. Interfaces, 2011, 3, 4853.

34 W. Luo, X. L. Hu, Y. M. Sun and Y. H. Huang, Phys. Chem. Chem. Phys., 2011, 13, 16735.

35 Y. M. Sun, X. L. Hu, J. C. Yu, Q. Li, W. Luo, L. X. Yuan, W. X Zhang and Y. H. Huang, Energy Environ. Sci., 2011, 4, 2870.

36 M. Ihsan, H. Q. Wang, S. R. Majid, J. P. Yang, S. J. Kennedy, Z. P. Guo and H. K. Liu, Carbon, 2016, 96, 1200.

37 Q. Yang, Q. Liang, J. Liu, S. Q. Liang, S. S. Tang, P. J. Lu and Y. K. Lu, Mater. Lett., 2014, 127, 32.

38 J. Liu, S. S. Tang, Y. K. Lu, G. M. Cai, S. Q. Liang, W. J. Wang and X. L. Chen, Energy Environ. Sci., 2013, 6, 2691.

39 S. S. Wang, B. C. Liu, G. L. Zhi, G. R. Xu, Q. Wang and J. Zhang, Microporous Mesoporous Mater., 2017, 246, 14. 